\title{
Monthly dynamics and biting behavior of principal onchocerciasis vector (Simulium damnosum s.l.) in endemic area of Southwest Ethiopia
}

\author{
Alemayehu Dagne Mose ${ }^{1}$, Behailu Taye $\mathrm{Mamo}^{1}$ and Solomon Yeshanew Alamirew ${ }^{2}$
}

1. Department of Biology, Faculty of Natural and Computational Science, Mettu University, P.O.Box:318, Mettu, Ethiopia; 2. Department of Biomedical Sciences, Faculty of Medical Science, Mettu University, P.O. Box: 318, Mettu, Ethiopia.

Corresponding author: Alemayehu Dagne Mose, e-mail: alemayehudagne@gmail.com Co-authors: BTM: behailu27taye@gmail.com, SYA: solarm12@yahoo.com

Received: 26-11-2019, Accepted: 07-01-2020, Published online: 16-02-2020

doi: www.doi.org/10.14202/IJOH.2020.23-27 How to cite this article: Mose AD, Mamo BT, Alamirew SY (2020) Monthly dynamics and biting behavior of principal onchocerciasis vector (Simulium damnosum s.I.) in endemic area of Southwest Ethiopia, Int. J. One Health, 6(1): 23-27.

\begin{abstract}
Background and Aim: Vector-borne diseases are the major causes of morbidity and mortality in several regions, especially in tropical and subtropical countries. This study aimed to compare the relative abundance, diversity, monthly biting rates, and parity rate of onchocerciasis vector collected from three small rivers in Southwest Ethiopia.

Materials and Methods: Adult Simulium were collected using human landing catch with protected by the Mosq Tent for 4 consecutive days per month from 7 a.m. to 6 p.m. from January 2018 to December 2018 at three communities: Dizi, Agalo Uka, and Haro Magela. Chi-square test was used to determine the association between study site villages and abundances of the Simulium diversity.

Results: During the study period, a total of 15,264 Simulium belong to two species Simulium damnosum sensu lato and Simulium neavei were collected. The monthly dynamics of $S$. damnosum sensu lato shows that the highest density of flies was observed in August, followed by July, whereas the lowest was observed in April. On the other hand, the highest peak biting hour was observed between 4 p.m. and 6 p.m., while the lowest hourly activity of the fly was recorded from 7 a.m. to 8 a.m. Furthermore, the highest parity rate was observed $82.2 \%$ in July followed by $80.9 \%$ in August while the lowest rate was observed $43.7 \%$ in January.

Conclusion: This information on onchocerciasis vectors seasonal variation, diversity, parity, and biting time are important factors that to be considered for noticeable suggestions in monitoring transmission levels to guide the regional and national onchocerciasis elimination programs in Ethiopia.
\end{abstract}

Keywords: onchocerciasis, parity, Simulium damnosum s.l., Simulium neavei, vector.

\section{Introduction}

Blackflies are arthropods found in order Diptera, family Simuliidae consists of 2189 species (2177 living and 12 fossils) in 19 genera, of which more than 40 are of medical and veterinary importance. Of these, approximately 60 Simulium damnosum theobald complex sibling species and cytoforms are documented in Africa [1]. Some of the most important genera of this family are Simulium, Prosimulium, Parasimulium, Australosimulium, Cnephia, and Gigantodax. Simulium species may transmit different microorganisms to human and animal hosts; for example, the virus causing vesicular stomatitis and the avian protozoan Leucocytozoon. They also act as vectors for Dirofilaria, Onchocerca, Mansonella, and Splendido filarial in humans, bears, cattle, ducks, and goose [2,3]. About 54 Simulium species have a role in biting and also transmitting of onchocerciasis in humans [4].

Copyright: Mose, et al. This article is an open access article distributed under the terms of the Creative Commons Attribution 4.0 International License (http://creativecommons.org/licenses/ by/4.0/), which permits unrestricted use, distribution, and reproduction in any medium, provided you give appropriate credit to the original author(s) and the source, provide a link to the Creative Commons license, and indicate if changes were made. The Creative Commons Public Domain Dedication waiver (http:// creativecommons.org/ publicdomain/zero/1.0/) applies to the data made available in this article, unless otherwise stated.
In Ethiopia, S. damnosum theobald complex which is widely distributed through an endemic and non-endemic area of the country is incriminated as the principal vector of onchocerciasis $[1,3]$.

According to the Global Burden of Disease Study estimate, there were 20.9 million prevalent Onchocerca volvulus infections worldwide in 2017: 14.6 million of the infected people had skin disease and 1.15 million had vision loss. More than $99 \%$ of infected people live in 31 African countries. In 2017, more than 142 million people were treated in Africa where the strategy of community-directed treatment with ivermectin was implemented, representing approximately $69.6 \%$ coverage of the number of people who require treatment globally [5]. In Ethiopia, people who live in fertile land of Southwest and Northwest Ethiopia who have extensive agricultural farming area and people who live and settle near to river banks were more vulnerable for onchocerciasis infection [6,7]. On the basis of Rapid Epidemiological Mapping of Onchocerciasis (REMO) [6] Southwest Ethiopia, including our current study area, is found endemic to onchocerciasis which is known by having many rivers with vegetation which create suitable habitat for onchocerciasis vector breeding site.

For successful disease elimination surveillance of adult vector biting activity, seasonal variation in vector density, abundance, and parity is pre-requisites 
in understanding vector-based epidemiology that serves for planning of effective vector control and mapping the target intervention area as sentinel area that serves as monitoring and surveillance of the vector. Therefore, this study was aimed to assess the monthly dynamics of onchocerciasis vector, parity, and biting behavior in the study area.

\section{Materials and Methods}

\section{Ethical approval and informed consent}

Ethical approval was obtained from Mettu University Research Affairs, Directorates Research Ethics Committee. No tissue samples were taken from human subjects; however, local data collectors were involved Simulium collections according to Nascimento-Carvalho et al. [8]. Signed informed consent was obtained from all individuals concerned after detailed explanations in their local languages Afan Oromo about the study.

\section{Study areas and period}

The study was conducted in Bure, Alle, and Nopha (Figure-1) districts of the southwest parts of Ethiopia. They are located around 500-700 km range from Addis Ababa in Ilu Aba Bor administrative zone. The districts are characterized by two rainy seasons, June-September - the main rainy season and MarchMay - the small rainy season and receive between 1300 and $1800 \mathrm{~mm}$ of annual rainfall and have a mean annual temperature of $19^{\circ} \mathrm{C}$. The collection of the flies was carried out from January 2018 to December 2018.

\section{Study site selection for Adult Simulium sampling}

In the localities, year-round streams and rivers were selected for sampling. The selection of the regions was based on characteristics such as nearby house, bioclimatic zone, mass drug administration (Mectizan/DEC/ Albendazole) distribution history, and variability, village size, and the features of the bank of the river. All information were gathered by visual observation and scored as either the absence or the presence of logs, trailing vegetation, and presence and absence of human activities.

\section{Sampling and identification}

The human landing catches with protected by the MosqTent were used for catching Adult Simulium. Fly catching was started from 7 a.m. to 6 p.m. for 4 consecutive days per month from January 2018 to December 2018. At breeding site selected, two fly catchers worked alternately for $6 \mathrm{~h}$ to make a total of $12 \mathrm{~h}$ per catching day. In each catching hour, they were rest for $15 \mathrm{~min}$. The fly collectors were sitting at the bank of the river followed the protocol adopted by Do Nascimento-Carvalho et al. [8]. Collected specimen of Simulium species was pooled according to the hour of the collection in each collection sites. The collected specimens were identified to species level on morphological basis keys [1,9]. Furthermore, the collected Simulium was labeled (including place, species name, date, and sampling method) and individually preserved in Eppendorf tubes.

\section{Adult Simulium parity determination method}

The flies caught on the $1^{\text {st }}$ day of every sampling were dissected for parity. The fresh Simulium with chloroform was placed on a microscope slide with a drop of phosphate-buffered saline solution surrounding the posterior part of the abdomen. On the sixth or seventh segments, dissection was made in the abdomen and the contents were pulled out gently. The ovaries were left on the slide to be dry. The ovaries were then studied under the microscope to determine whether they were nulliparous or parous. The nulliparous condition is indicated by the tightly coiled endings to the tracheoles (skeins) while the parous female has uncoiled endings. The female Simulium that has taken a blood meal and has laid their eggs at least once is parous, while those that have not taken a blood meal and laid their eggs are nulliparous [10].

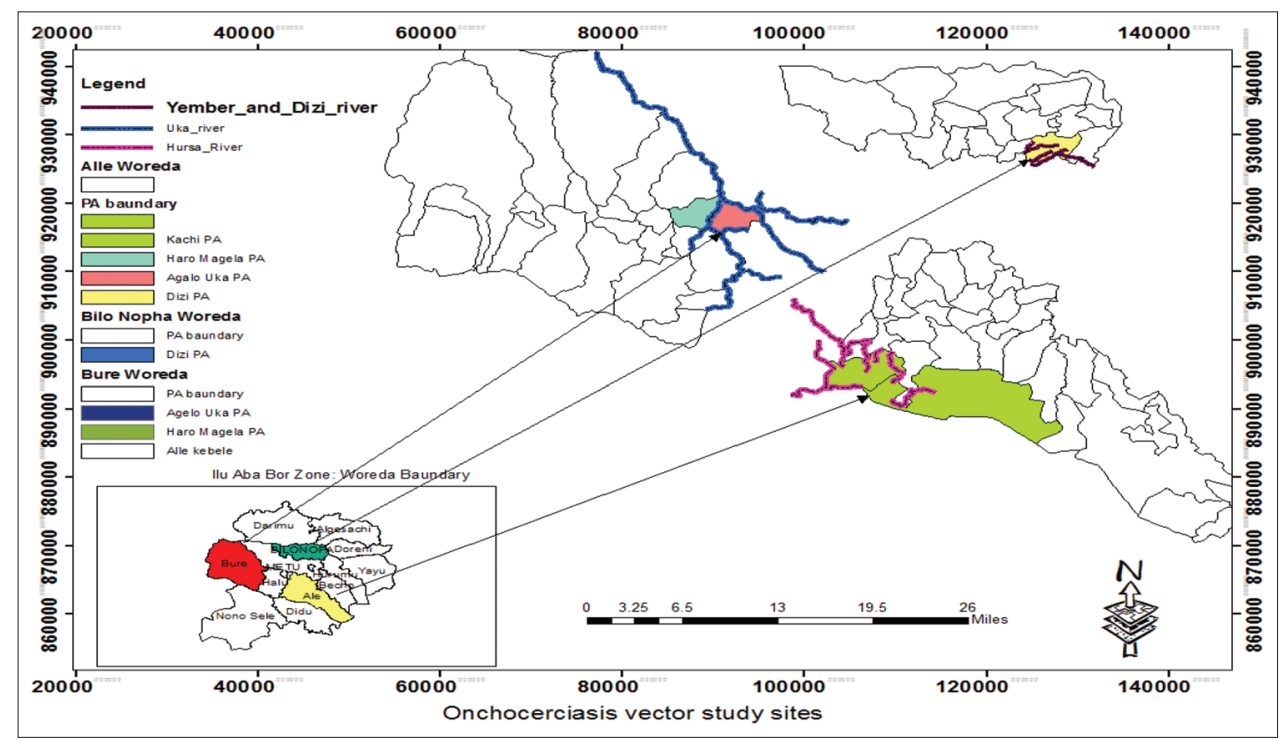

Figure-1: Onchocerciasis vector study sites. 


\section{Results}

\section{Species diversity and abundance of Simulium}

A total of 15,264 flies belong to two species S. damnosum s.l. and Simulium neavei were collected from Dizi 4873 (31.84\%), Haro Magela 5191 (33.92\%), and Agalo Uka 5241 (34.24\%), respectively, S. damnosum s.1. was predominant species 14,960 (97.75\%) followed by $S$. neavei 345 (2.25\%) (Tables-1 and 2). The Chi-square test revealed that there is no association (Chi-square $=88.80, \mathrm{df}=90, \mathrm{p}=0.516$ ) between study site villages and abundances of the Simulium diversity.

\section{Temporal dynamics of Simulium}

The monthly dynamics of $S$. damnosum s.1. shows that the highest density of flies was observed in August followed by July, whereas the lowest was observed in April. On the other hand, S. neavei density was shown more or less similar trends between months (Figure-2).

\section{Hourly peak biting time of Simulium}

The highest peak biting hour was observed between 4 p.m.-5 p.m. and 5 p.m.-6 p.m. while the lowest hourly activity of the fly was recorded from 7 a.m. to 8 a.m. Furthermore, the high activities of Simulium start from 3 p.m. - goes to the peak (Figure-3). On the other hand, the highest commutative monthly based peak hourly biting activities of $S$. damnosum s.l. were observed at 10 a.m.-11 a.m. (Figure-4).

Monthly parity rate of S. damnosum s.I. and infectivity

The highest parity rate was observed in July $82.2 \%$, followed by August $80.9 \%$, while the lowest rate was observed in January $43.7 \%$ mean (Table-2).

\section{Discussion}

There is no association between study site and abundance of Simulium in the study area, this may be due to the uniform suitability of the area for vector breeding, the distance between the rivers and community settlement, and the water current are similar and could be the factors of their association, this finding is agreed with Guacaneme et al. [11]. The highest number of Simulium was sampled in August, July, and September, this might be due to relatively high rainfall and relative humidity present in the period because it is rainy season for the study area. During rainy season, the amount and current of water in the rivers would increase more it may create conducive environment for the proliferation and growth of Simulium larvae in the river since the larvae are filter feeders that depend on the water current of the rivers, streams, and spring this finding in lined with Chikezie et al. [12] study. On the other hand, the predominant Simulium in the study area is $S$. damnosum s.l even though in the complex level, the group encompasses primary river blindness vectors in which almost all the cases reported elsewhere belong to this Simulium group [13,14].

The diurnal biting activities of $S$. damnosum s.l. showed a similar pattern both spatially and temporally in each habitat type and study period, respectively.

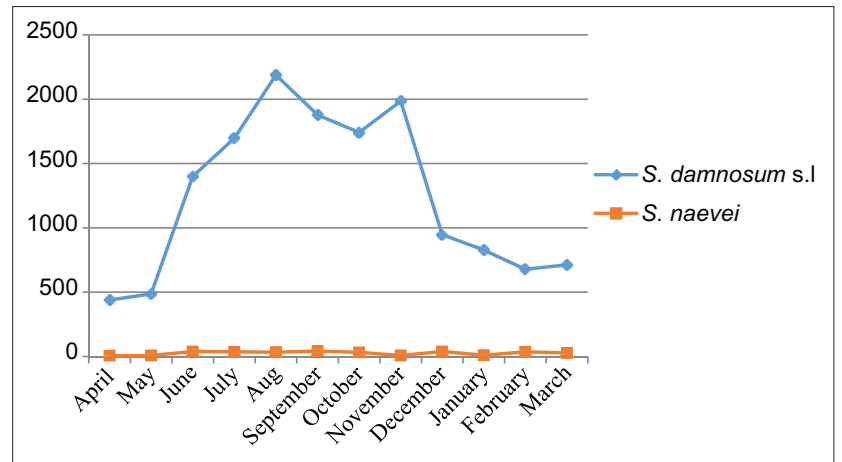

Figure-2: Monthly density of Simulium in the study areas, Ilu Aba Bor zone, Southwest Ethiopia, 2018.

Table-1: The Simulium abundance and diversity between the study sites Ilu Aba Bor zone Southwest Ethiopia, 2018.

\begin{tabular}{lccccc}
\hline Villages & Dizi & Haro Magela & Agalo Uka & Total & Percentage \\
\hline Simulium damnosum s.I & $4,758(31.09 \%)$ & $5,065(33.09 \%)$ & $5,137(33.56 \%)$ & 14,960 & 97.75 \\
Simulium naevei & $115(0.75 \%)$ & $126(0.82 \%)$ & $104(0.68 \%)$ & 345 & 2.25 \\
Total & $4,873(31.84 \%)$ & $5,191(33.92 \%)$ & $5,241(34.24 \%)$ & 15,305 & 100.00 \\
\hline
\end{tabular}

Table-2: The parity rate of Simulium damnosum s.I. in the study period Ilu Aba Bor zone, Southwest Ethiopia, 2018.

\begin{tabular}{|c|c|c|c|c|c|}
\hline Month & Total dissected & Parous & Nulliparous & Failed & Parity rate $(\%)$ \\
\hline April & 60 & 27 & 33 & & 45 \\
\hline May & 74 & 40 & 34 & & 54 \\
\hline June & 66 & 33 & 33 & & 50 \\
\hline July & 90 & 74 & 16 & & 82.2 \\
\hline August & 110 & 89 & 18 & 3 & 80.9 \\
\hline September & 100 & 63 & 35 & 2 & 63 \\
\hline October & 78 & 56 & 22 & & 71.8 \\
\hline November & 55 & 23 & 33 & 1 & 41.8 \\
\hline December & 48 & 24 & 24 & & 50 \\
\hline January & 48 & 21 & 27 & & 43.7 \\
\hline February & 51 & 23 & 27 & 1 & 45.1 \\
\hline March & 49 & 18 & 31 & & 36.7 \\
\hline Total & 829 & 491 & 333 & & 55.4 \\
\hline
\end{tabular}




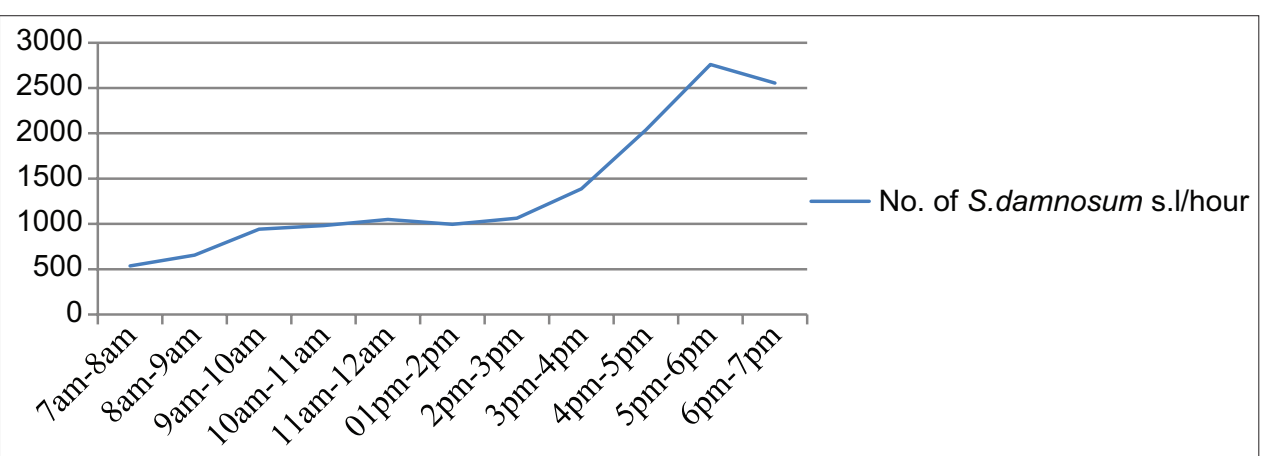

Figure-3: Diurnal hourly density of Simulium damnosum s.l. of Ilu Aba Bor zone, Southwest Ethiopia, 2018.

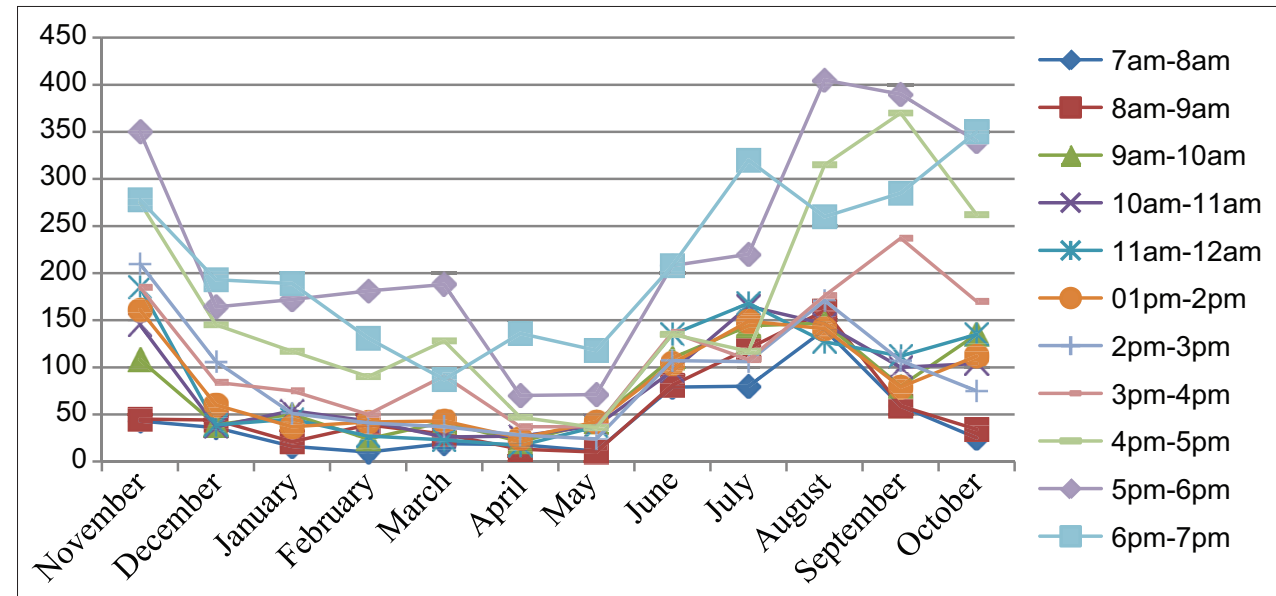

Figure-4: Monthly diurnal biting activities of Simulium in Ilu Aba Bor zone, Southwest Ethiopia, 2018.

Nevertheless, the high tendency of the highest peak biting hours was observed between 4 p.m.-5 p.m. and 5 p.m.-6 p.m [15] when high activities such as fetching water, collecting firewood, conducting agricultural activities, and keeping cattle were the most common activities which were conducted by inhabitants. This might be the behavioral evolution exhibited by the vector [9] because both the host and vector activities synchronized at the similar time which might have high probability of being bitted as well as infected by the onchocerciasis [16].

The parity rate of $S$. damnosum s.l. at each month showed more than $50 \%$, which means the majority of them were older Simulium found on the period. The more old population of Simulium found in the area the more probability of maturity of the parasite in the vector; this means that there is a high chance of being infected by the diseases. Because the more parous Simulium is found in the population high longevity of the vector also increases if long-lived Simulium more in the study area and period infection of the disease increase, on the other hand, parous vector often shows at least one, the vector had fed blood from the host. Our investigations on parity patterns of the $S$. damnosum s.l showed that the highest parous flies were observed in the period furthermore, the highest density of Simulium obtained in July and August months. High probability of infection again may happen in this month's which permit, together with
O. volvulus infection rates reported elsewhere [17] which makes our current study area conducive environment for Simulium breeding site [7,18]. Therefore, having knowledge on peak biting time and high parous rate provides useful information for the design of entomological evaluation protocols for the monitoring of onchocerciasis vector control and onchocerciasis elimination programs.

\section{Conclusion}

The current finding showed that $S$. damnosum s.l is the predominant Simulium species in the area. Since this fly is the primary vector and responsible for majority cases of onchocerciasis, elsewhere hence every responsible body from government to individual should take care and find the possible vector control methods to reduce the risks in the study area. On the other hand, the highest peak biting time of the Simulium was started from 4 p.m. to 6 p.m., whereas the rainy season including June to September was the time with the highest density and parity being registered, respectively. This information lets the clue time to which intervention should be taken and supports the national and regional onchocerciasis elimination programs in Ethiopia. Furthermore, the local community should care for themselves by wearing protective close while they go to river for fetching water, particularly the time and season that flies density become peaked. 


\section{Authors' Contributions}

ADM equipped the work. ADM and BTM performed the field study and data entry. ADM, BTM and SYA did analysis. ADM and BTM drafted and revised the manuscript. All authors read and approved the final version of the manuscript.

\section{Acknowledgments}

The authors are grateful to Mettu University for financial support from Internal Research Fund of Mettu University, Ethiopia (Grant no. 6223) and our appreciation extended for communities of Haro Magela, Agalo Uka, and Dizi villages where samples were collected for their cooperation and to our entire field and laboratory technician for assistance during the fieldwork and laboratory work.

\section{Competing Interests} interests.

The authors declare that they have no competing

\section{Publisher's Note}

Veterinary World (Publisher of International Journal of One Health) remains neutral with regard to jurisdictional claims in published map and institutional affiliation.

\section{References}

1. Peter, H.A. and Roger, W.C. (2019) "World Blackflies (Diptera: Simuliidae): A Comprehensive Revision of the Taxonomic and Geographical Inventory." Natural History Museum. p109. Available from: https://www.biotaxa. org/Zootaxa/article/view/zootaxa.4455.1.2. Retrieved on 17-04-2019.

2. Adler, P.H. and McCreadie., J.W. (2019) Black Flies (Simuliidae). In: Gary, R.M. and Lance, A.D., editors. Medical and Veterinary Entomology. Published by Elsevier Inc, London, UK. p236-253.

3. Taylor, M.A., Coop, R.L. and Wall, R.L. (2007) Veterinary Parasitology. $3^{\text {th }}$ ed. Blackwell Publishing, Oxford, UK. p88.

4. Adler, P.H., Currie, D.C. and Wood, D.M. (2004) The Black Flies (Simuliidae) of North America. Cornell University Press. Ithaca, New York. 941 p+24 color plates.

5. WHO, Onchocerciasis. (2018) Available from: https:// www.who.int/news-room/fact-sheets/detail/onchocerciasis. Retrieved on 17-04-2019.

6. Meribo, K., Kebede, B., Feleke, S.M., Mengistu, B., Mulugeta, A., Sileshi, M., Samuel, A., Deribe, K. and Tadesse, Z. (2017) Review of Ethiopian onchocerciasis elimination programme. Ethiop. Med. J., 55 (Suppl 1): 55-63.

7. Federal Democratic Republic of Ethiopia Ministry of Health. (2016) Ethiopia National Master Plan for Neglected
Tropical Diseases, $2^{\text {nd }}$ ed. Federal Democratic Republic of Ethiopia Ministry of Health, Addis Ababa, Ethiopia. Available from: http://www.espen.afro.who.int/system/files/content/resources/ETHIOPIA_NTD_Master Plan 2016 2020.pdf. Retrieved on 17-04-2019.

8. Do Nascimento-Carvalho, É.S., De Andrade Cesário, R., Do Vale, V.F., Aranda, A.T., Dos Santos Valente, A.C. and Maia-Herzog, M. (2017) A new methodology for sampling blackflies for the entomological surveillance of onchocerciasis in Brazil. PLoS One; 12(7): e0179754.

9. Service, M.W. (1993) Mosquito Ecology and Fieldsampling Methods. $2^{\text {nd }}$ ed. Applied Science Publishers Limited., London, UK. p56-100.

10. Lamberton, P.H.L., Cheke, R.A., Walker, M., Winskill, P., Osei-Ateweneboana, M.Y., Tirados, I., Tetteh-Kumah, A., Boakye, D.A., Wilson, M.D., Post, R.J. and Basáñez, M.G. (2014) Onchocerciasis transmission in Ghana: Biting and parous rates of host-seeking sibling species of the Simulium damnosum complex. Parasit. Vectors, 7 (2014): 511.

11. Guacaneme, A.B., Sotelo-Londoño, A., Pinilla-Agudelo, G., García-García, A., Moncada, L. and Adler, H.P. (2018) Abundance and diversity of black flies (Diptera: Simuliidae) in rivers of the Andean Eastern Hills of Bogotá (Colombia), and its relationship with waterstream physicochemical variables. Univ. Sci., 23(2): 291-317.

12. Chikezie, F.M., Uzoigwe, N.R., Opara, K.N. and Ezihe, E.K. (2018) Seasonal variations in biting density and infectivity of Simulium damnosum complex in Ezeagu and OjiRiver local government areas of Enugu State, Nigeria. Ann. Res. Rev. Biol., 24(2): 1-10.

13. Anong, C., Akinboade, O., Abiola, J., Uwalaka, E. and Adediran, A. (2015) Scientific causal analysis of river blindness: A type of onchocerciasis specifically found in Northern Nigeria. World Rural Obs., 7(2): 55-60.

14. Goselle, O.N., Joshua, S.M., Chinedu, O.U., Ngoh, B.J., Wuyep, P.A., Chaksda, A. and Mafuyai, H.B. (2017) Study on population dynamics of black flies imagos. J. Entomol. Zool. Stud., 5(1): 530-539.

15. Eyo, J.E., Ikechukwu, E.O., Ubachukwu, P.O., Ivoke, N. and Ekeh, F.N. (2014) Effects of climatic conditions on the biting density and relative abundance of Simulium damnosum complex in a rural Nigerian farm settlement. Ann. Agric. Environ. Med., 21(4): 697-700.

16. Adeleke, M., Mafiana, C., Sam-Wobo, S., Olatunde, O., Uwem, F., Ekpo, U., Akinwale, O. and Toe, L. (2010) Biting behaviour of Simulium damnosum complex and Onchocerca volvulus infection along the Osun River, Southwest Nigeria. Parasites Vectors, 3:93.

17. Myburgh, E. and Nevill, E.M. (2003) Review of Blackfly (Diptera: Simuliidae) Control in South Africa. Onderstepoort J. Vet. Res., 7:39.

18. Zarroug, I.M.A., Hashim, K., Elaagip, A.H., Samy, A.M., Frah, E.A., ElMubarak, W.A., Mohamed, H.A., Deran, T.C.M., Aziz, N. and Higazi, T.B. (2016) Seasonal variation in Biting Rates of Simulium damnosumsensu lato, vector of Onchocerca volvulus, in two Sudanese foci. PLoS One, 11(3): 1-15. 